\title{
Studying (Small) Businesses with the Michigan Employment Security \\ Commission Longitudinal Data Base*
}

Charles Brown

Judith Connor

Steven Heeringa

John Jackson

\begin{abstract}
This paper addresses the usefulness of a longitudinal data file constructed from records on employers from the Michigan Employment Security Commission. We describe the main features of the data file, which includes quarterly (and in some cases, monthly) data from the third quarter of 1978 through the first quarter of 1983, plus the fourth quarters of 1983-87. We then illustrate the uses of the data with two examples: (1) studying changes in the Michigan economy, in particular the early growth and survival of new units of different sizes; and (2) studying the behavior of wages and employment following changes in ownership.
\end{abstract}

\section{Introduction}

Recent interest in studying the dynamics of firm growth, particularly with a focus on small business, has led to a subtle change in the type of data used to study firms. The need to focus on firms too small to be represented in files of companies whose stock is publicly traded has led researchers to discover or to create files from data which nearly all firms report for other purposes. The data on Michigan firms, based on the records of the Michigan Employment Security Commission (MESC) is an example of this strategy.

Under a contract from the State of Michigan, the University of Michigan Survey Research Center constructed a longitudinal data base from the quarterly ES202 files produced by the MESC.

Final version accepted on June 14, 1990

Institute for Social Research

The University of Michigan

Ann Arbor, MI 48109

U.S.A.
This data base has been used by researchers at the University of Michigan to study firm-level employment and payroll changes during different parts of the business cycle. In addition, analyses were done by University staff at the request of various state government agencies. The period covered by the original data base was the third quarter of 1978 through the first quarter of 1983. There have been three updates to this file: The data base currently includes all quarters through the fourth quarter of 1988 .

This paper is organized as follows. The second section will describe the data fields in the MESC files which were used in constructing the data base, the special predecessor/successor relationships which exist when the firms change ownership, and the process of constructing the longitudinal data base. The third section will describe a set of analyses which use the longitudinal data base to study firm-level employment change (births, deaths, growth, decline) by industry over time. The fourth section describes a second example of the use of the MESC longitudinal data base - an analysis which compares the employment level and average wage of firms before and after mergers or other changes of ownership. The final part briefly discusses other potential uses of the data, plans for updates, and the availability of the data to researchers.

\section{The MESC longitudinal data base}

\section{A. MESC files}

The MESC receives quarterly payroll and employment reports from all employers in Michigan which are required by law to participate in the unemployment insurance program. This includes 
all firms with at least one Michigan employee. The U.S. Department of Labor requires state employment security commissions to collect employment data by Standard Industrial Classification (SIC) code and county and to file ES202 reports every quarter. In order to administer the unemployment compensation program and to comply with the Department of Labor regulations, the MESC maintains an information system with records for each Michigan employer containing monthly employment, quarterly payroll, county, and SIC code. The quarterly ES202 reports are compiled from this information. If an employer is delinquent in filing a quarterly report, the employment and payroll information are estimated by MESC and the imputed fields are flagged as estimates in the ES202 file.

In addition to the ES202-related information, the MESC maintains a record of information needed to determine the unemployment insurance rate to be paid by each employer. These data fields include "experience beginning date", predecessor/ successor information (which allows one to distinguish between new firms and changes of ownership of existing ones) ${ }^{1}$, and the actual insurance rate charged to the employer based on its record of layoffs of employees. This set of information was originally contained in an Employer Master Record (EMR). ${ }^{2}$

The EMR file used in building the original MESC longitudinal data base was the 1983 first quarter version and consisted of 326,446 records. This file contained a nearly complete record of Michigan firms from 1937 through the first quarter of 1983. The file as received contained records for terminated firms, inactive firms, and "predecessor" firms in addition to currently active firms. In constructing the longitudinal data base, firms which terminated without a successor prior to 1977 were excluded because the ES202 files for the period prior to 1977 were not available.

Further information about the EMRs and ES202 records is presented in the Appendix.

\section{B. Longitudinal data file}

The process of building a longitudinal analysis file is complicated, but the resulting file can be much more easily understood. For the simplest case, a single-location firm which underwent no change of ownership, the data would include the EMR data plus quarterly ES202 data for the third quarter of 1978 through the first quarter of 1983. Firms which were born (or died) during this period would have no ES202 data for quarters preceding the birth (or following the death).

For firms which have changes of ownership, and therefore have predecessor/successor relationships, matters are a bit more complicated. The longitudinal file contains the ES202 data of the successor, and (in separate fields) the aggregate total of predecessor data for quarters prior to the change in ownership. The predecessor employment and payroll then vanishes after the (last) change of ownership has occurred.

\section{Using the data base in analysis}

When analyses are done to measure change in employment or payroll from one time period to another, the employment or payroll from the predecessor firms should be included for each time period being compared. This can be done by adding the corresponding current company and predecessor company fields. Including the predecessor companies in analyses of change insures that the changes which are computed reflect the true change which occurred. If predecessor companies are not included in an analysis, the change could be magnified. For example, if company A bought company B in 1979, company B would be a predecessor of company $A$. If company $A$ and company B each had 100 employees in 1979 and the current company A in 1983 had 300 employees, the true change is $300-200$ or an increase of 100 employees. Ignoring the predecessor company would couse the increase for Company $A$ to be 200 employees. In addition, ignoring predecessor records would give counts of company "births" and "deaths" which are too high.

The MESC longitudinal data base has been used to study firm-level change over time. In this type of analysis, a time period is selected - for example, the fourth quarter of 1979 through the fourth quarter of 1984. Firms are then classified into four categories: (1) firms which existed prior to the beginning point and continued in existence throughout the period; (2) firms which were born during the period and continued in existence; (3) firms which existed prior to the beginning point 
and died before the ending point; and (4) firms which were born and died during the period. Type 1 or "continuing" firms can be further subdivided into growing or declining firms - those which added employees (or payroll) and those which lost employees (or payroll). The distribution of "births," "deaths," growing and declining firms can be found for different industries, employment size categories, or counties.

The Experience Date can serve as the birth date in all but a few unusual cases. ${ }^{3}$ However, the Termination Date does not serve well as the date of death. Often this date is several quarters later than the actual "death" of a company. One way of determining the date of death is to define the quarter of death as the first of four consecutive quarters of no employment or missing data on employment following one or more quarters of reported employment. A quarter with an " $E$ " in the "All Data Estimated" field should also be counted as a quarter of no employment in calculating the date of death of a company.

\section{The changing structure of the Michigan economy, 1978-1987: Seeing the trees through the forest}

An economy is better visualized as a biological than as a mechanical system. It is a forest, not a machine. Examining the trees through the forest, it is clear that the forest, even when it appears stable, is a very dynamic and ever changing entity. Countless numbers of seedlings are born and a few grow into saplings, some saplings develop into mature trees, and mature trees eventually decay and fall or are harvested. The long-term health of the forest depends upon this continual process of birth and maturation. Anything that disrupts or halts any part of this process threatens the long-term health of the forest.

Likewise, this is true for the health of any economy. What may seem to be a stable, unchanging economic structure is really made up of many separate firms going through a life cycle similar to that of individual trees. Firms are born, some of which survive to develop into viable enterprises. These enterprises then mature and may gradually decline or suddenly die-and be replaced by new enterprises. Change in the number of jobs in an economy comes about in four specific ways. New jobs are added by growing firms and by new firms. Jobs are lost when firms contract employment or go out of business. As with the forest, these can be quite different processes. To get an accurate picture of the changing structure of the Michigan economy, we must measure these four components separately, which the MESC data, updated to 1987 , allow us to do.

Despite being documented only fairly recently, the volatility of employment at the firm or establishment level is one area of clear agreement among researchers studying the issue (Armington and Odle, 1982; Birch, 1981 and 1987; Dunne, Roberts, and Samuelson, 1989; Leonard, 1987; U.S. Small Business Administration, 1988; Acs and Audretch examine reasons for differences in volatility across industries, 1989). We add to this literature in two ways. First, we show that the now well-known volatility exists even within individual industries within a particular state - new seedlings arise in the very same parts of the forest in which old trees are dying. Second, we can trace this process in industries of particular interest. In the context of the large swing from durable manufacturing to services in Michigan, the fortunes of the machine tool and computer software industries are of particular interest. ${ }^{4}$

\section{A. Components of changes: Manufacturing}

In manufacturing, 126,300 jobs were added to the economy by the 3,963 firms that grew between 1978 and 1987. Another 103,300 jobs were added by 5,289 firms new to Michigan in that same period. Simultaneously, the state lost 347,300 jobs because of 3,610 shrinking firms and 116,100 jobs due to 4,217 firms that quit doing business in the state. These changes led to the net loss of 233,800 manufacturing jobs. Decreases in auto assembly employment by the four large car companies comprise over $50 \%$ of the jobs lost by shrinking manufacturing firms. If we exclude the automobile industry (SIC 371) from these figures, there is a net loss of 42,200 jobs, of which 140,400 were in shrinking firms and 109,200 in firms that failed. These data give a more representative picture of the changes that occurred in the Michigan manufacturing economy between 1978 and 1987. Table I gives the manufacturing job gains and losses by sector. 
TABLE I

The Michigan manufacturing economy: 1978-1987

\begin{tabular}{|c|c|c|c|c|c|}
\hline SIC & Growth & Births & Declines & Failures & Net Change \\
\hline \multicolumn{6}{|l|}{ Employment } \\
\hline Food products & 8885 & 4266 & -9346 & -9512 & -5708 \\
\hline Textile products & 76 & 317 & -367 & -89 & 1326 \\
\hline Apparel & 3071 & 1326 & -1151 & -1705 & 1540 \\
\hline Lumber \& wood & 2618 & 4856 & -2218 & -5592 & -335 \\
\hline Furniture & 9010 & 3216 & -3754 & -2106 & 6366 \\
\hline Paper & 5093 & 2504 & -3025 & -5593 & -1021 \\
\hline Publishing & 8280 & 5628 & -3208 & -4085 & 6615 \\
\hline Chemicals & 211 & 3129 & -7598 & -1808 & -1066 \\
\hline Petroleum & 326 & 233 & -139 & -253 & 167 \\
\hline Nondurables & 42570 & 25477 & -30807 & -30743 & 6496 \\
\hline Rubber \& plastic & 11928 & 8496 & -8375 & -6576 & 5473 \\
\hline Leather & 304 & 120 & -1517 & -335 & -1428 \\
\hline Stone, clay, glass & 2928 & 2164 & -5939 & -3635 & -4482 \\
\hline Primary metals & 3295 & 6688 & -19709 & -6932 & -16657 \\
\hline Fabricated metals & 17683 & 15533 & -22502 & -22013 & -11299 \\
\hline Machinery & 18363 & 20822 & -45225 & -24752 & -30791 \\
\hline Electric machinery & 6840 & 4629 & -4569 & -7482 & -582 \\
\hline Transportation & 18114 & 13689 & -203103 & -10455 & -181755 \\
\hline Instruments & 2716 & 4182 & -2660 & -1502 & 2736 \\
\hline Miscellaneous & 1583 & 1459 & -2916 & -1641 & -1515 \\
\hline Durables & 3754 & 77781 & -316514 & -85322 & -240302 \\
\hline Manufacturing & 126324 & 103257 & -347321 & -116066 & -233805 \\
\hline Meg. excl. auto & 115298 & 92102 & -140396 & -109161 & -42156 \\
\hline
\end{tabular}

Number of firms

\begin{tabular}{|c|c|c|c|c|c|}
\hline Food products & 151 & 136 & 191 & 220 & -84 \\
\hline Textile & $*$ & * & $*$ & $*$ & 15 \\
\hline Apparel & 48 & 98 & 59 & 105 & -7 \\
\hline Lumber \& wood & 235 & 508 & 184 & 463 & 45 \\
\hline Furniture & 94 & 151 & 67 & 80 & 71 \\
\hline Paper & 68 & 66 & 56 & 50 & 16 \\
\hline Publishing & 493 & 717 & 275 & 447 & 270 \\
\hline Chemicals & 84 & 130 & 89 & 85 & 45 \\
\hline Petroleum & 18 & 18 & 14 & 14 & 4 \\
\hline Rubber \& plastics & 261 & 295 & 125 & 150 & 145 \\
\hline Leather & $*$ & $*$ & $*$ & $*$ & -4 \\
\hline Stone, clay, glass & 134 & 130 & 177 & 179 & -49 \\
\hline Primary metals & 104 & 159 & 176 & 140 & 19 \\
\hline Fabricated metals & 690 & 733 & 644 & 689 & 44 \\
\hline Machinery & 1110 & 1369 & 1169 & 1102 & 267 \\
\hline Electric machinery & 109 & 183 & 97 & 114 & 69 \\
\hline Transportation & 170 & 277 & 129 & 179 & 98 \\
\hline Instruments & 86 & 130 & 68 & 62 & 68 \\
\hline Miscellaneous & 96 & 155 & 78 & 114 & 41 \\
\hline Total & 3963 & 5289 & 3610 & 4217 & 1072 \\
\hline
\end{tabular}


A significant measure of the health of the economy is the growth rate of the expanding firms. Long-term health requires that there be substantial growth among these enterprises, otherwise the economy can become stagnant and growth will not offset the declines occurring in mature firms. In Michigan during this period, the aggregate employment growth rate of the growing firms was $70.3 \%$, or a compound annual growth rate in excess of $6 \%$. These results indicate that the state has a core of quite successful expanding manufacturing enterprises.

The side by side occurrence of growth and decline and birth and death is not a consequence of aggregating changes in different industries going in different directions. These changes occur within even narrowly defined industrial sectors. To illustrate this point, examine the machine tool industry (SIC 354). This industry is central to the durable goods manufacturing economy, as the machine tool industry makes the equipment that make other products, such as cars, ball point pens, and widgets. This is also an industry experiencing a considerable amount of technological change. Growing firms equaled declining firms in numbers (642 each) and new firms exceeded deaths, 659 to 567. Growing firms and new firms each added 8,400 jobs. Total employment, however, declined by 11,700 jobs as shrinking firms lost 15,000 jobs and the failures costs the state 13,500 jobs. Thus, even within this one industry, there is considerable evidence of growth and new activity even though on net the industry employment is shrinking. Data on industry growth rates may tell us nothing about individul firms.

Comparisons of growth and decline in the machine tool industry suggest that growth most likely occurs in smaller firms and decline is more characteristic of larger, and possibly more mature, firms. The 642 growing firms employed 13,866 people in 1978 , an average of 21.6 jobs/firm. (The new firms average 12.8 workers per firm in 1987.) In contrast, the 642 shrinking firms employed 32,644 people and the 567 failed firms contained 13,485 jobs, per firm averages of 50.8 and 23.8 jobs/firm respectively. Combined, the declining and failed firms had an average size of 38.2 workers/firm. Of course, it is quite possible that the failed firms, though only averaging 24 jobs per firm in 1978 had been larger than that in previous years. Thus, we see a clear pattern of growth taking place among new and smaller firms.

\section{B. Components of change: Financial and nonfinancial services}

The service sectors (finance and other services), and business services in particular, are touted as the growth sectors of the U.S. economy and their pattern of change provides a stark contrast to the experiences in manufacturing. For services, and for business services specifically (SIC 73 and 89), by far the largest component of change was that of jobs added by new firms. The new firms added 179,800 jobs, of which 102,100 were in business services. There were 20,400 new firms behind these 179,800 new jobs, 8,800 in business services. There were only 5,800 declining firms, losing 60,000 jobs, and 14,400 firms that went out of business, which led to 97,100 jobs being lost. The growing service firms had an average growth rate of $87.5 \%$ and the growth rate among the growing business service firms was $136.2 \%$ ! The difference between services and manufacturing is one of maturity. Table II gives the changes by detailed sector.

Services have far fewer older enterprises, and are characterized by young faster growing firms. This is a very young forest, with many young and new fast growing trees. Manufacturing, by contrast, has a much different mix of young and mature, large and small, and growing and declining firms (trees).

Computer software (SIC 737), exclusive of the move of EDS from Texas to Michigan following its purchase by GM, provides a very detailed look at a young, relatively new and growing industry. $82.4 \%$ of the firms in existence in 1987 did not exist in 1978 and $50 \%$ of the jobs present in 1987 are in these new firms. These 786 new firms added 8,400 jobs to the Michigan economy. In contrast, the 105 growing firms added 3,300 jobs while declining and failed firms lost a total of 2,560 jobs. Including the expansion of EDS following its purchase by GM adds substantially to these numbers, as that action added over 10,000 new jobs to the Michigan economy. ${ }^{5}$ In the case of computer software, industry growth does a good 
TABLE II

The Michigan business service economy: 1978-1987

\begin{tabular}{|c|c|c|c|c|c|}
\hline SIC & Growth & Births & Declines & Failures & Net Change \\
\hline \multicolumn{6}{|l|}{ Employment } \\
\hline Banking & 13528 & 1013 & -1945 & -6569 & 6027 \\
\hline Credit agencies & 9533 & 2913 & -1154 & -3812 & 7480 \\
\hline Security brokers & 3063 & 1279 & -60 & -347 & 3934 \\
\hline Insurance carriers & 7807 & 1585 & -6883 & -1559 & 950 \\
\hline Insurance agents & 3720 & 4951 & -1743 & -2959 & 3970 \\
\hline Real estate & 5915 & 11824 & -7871 & -8911 & 957 \\
\hline Real estate $\&$ insur. & 27 & 76 & -29 & -50 & 24 \\
\hline Other invest. offices & 692 & 1548 & -848 & -531 & 862 \\
\hline Finance & 44284 & 25190 & -20533 & -24737 & 24203 \\
\hline Hotels & 4405 & 12194 & -4846 & -7639 & 4114 \\
\hline Personal services & 7293 & 13504 & -4988 & -11800 & 4009 \\
\hline Business services & 54786 & 83973 & -12418 & -24726 & 101615 \\
\hline Garage $\&$ auto repair & 4663 & 13272 & -2592 & -8176 & 7166 \\
\hline Misc. repair & 2002 & 5081 & -1453 & -3800 & 1830 \\
\hline Motion pictures & 1263 & 1191 & -1079 & -1860 & -486 \\
\hline Recreation services & 4174 & 7243 & -4240 & -7162 & 15 \\
\hline Professional services & 10909 & 18104 & -7835 & -7192 & 13986 \\
\hline Services & 89494 & 154563 & -39451 & -72356 & 132249 \\
\hline
\end{tabular}

Number of firms

\begin{tabular}{|c|c|c|c|c|c|}
\hline Banking & 210 & 42 & 76 & 420 & 0 \\
\hline Credit agencies & 455 & 224 & 182 & 268 & -44 \\
\hline Security brokers & 55 & 241 & 17 & 60 & 180 \\
\hline Insurance carriers & 132 & 212 & 123 & 119 & 103 \\
\hline Insurance agents & 785 & 1330 & 478 & 912 & 418 \\
\hline Real estate & 738 & 2127 & 656 & 2430 & -303 \\
\hline Real estate \& insur. & 12 & 40 & 12 & 24 & -20 \\
\hline Other invest. offices & 32 & 200 & 29 & 100 & 100 \\
\hline Finance & 2419 & 4380 & 1573 & 3955 & 425 \\
\hline Hotels & 295 & 607 & 290 & 642 & -35 \\
\hline Personal services & 950 & 2253 & 1000 & 2567 & -314 \\
\hline Business services & 1328 & 6425 & 910 & 2580 & 3845 \\
\hline Garage $\&$ auto repair & 798 & 2366 & 662 & 1756 & 610 \\
\hline Misc. repair & 364 & 1031 & 335 & 808 & 223 \\
\hline Motion pictures & 49 & 162 & 55 & 157 & -5 \\
\hline Recreation services & 495 & 794 & 443 & 788 & 6 \\
\hline Professional services & 792 & 2371 & 541 & 1143 & 1228 \\
\hline Services & 5071 & 16009 & 4236 & 10441 & 5568 \\
\hline
\end{tabular}

job of depicting what is happening to individual firms because of the relative newness of the entire industry and the homogeneity of firms within the industry.

\section{New and small enterprises and the Michigan economy}

What types of firms are gaining and losing jobs?
Much of the current debate focuses on the importance of new, small, relocating, and large firms in creating new jobs. Similarly, we want to know the types of firms that are losing jobs. This analysis will provide the most detailed information available to add to this debate.

New firms in the MESC data consist of two quite different types of enterprises. The first are new indigenous starts, which fit our concept of the 
entrepreneurial firm. The second are transplants, which can be entire firms that relocate to the state or new branch plants of out-of-state firms. In terms of economic development policy, starts and transplants are quite different and are the focus of very different strategies. Thus, we would like to know something about the relative importance of each in creating jobs. Unfortunately, the MESC data do not contain information to distinguish between these two types of new firms.

A first cut on making the separation between new firms and transplants is by the size of the firm when it first appears in the data base. Presumably the larger enterprises were transplanted to Michigan while the smaller ones are the ones originating within the state. We will use 20 employees as the threshold, recognizing that this is very arbitrary. It seems unlikely that enterprises that begin with 20 or fewer employees are transplants. At the same time, it may well be that some firms that begin with more than 20 employees are true starts. The higher the threshold, the more certain we are that the large category contains only transplants, but the more likely the lower category is to contain new starts and transplants.

The sources of job creation and loss are easily illustrated by looking at the number of jobs created by new firms and by firms of different sizes in 1978. Table III gives the numbers of jobs gained and lost by size and sector (with losses by

TABLE III

Job cain and loss by firm size: $1978-1987$

\begin{tabular}{lrrrr}
\hline & MFG & Finance & Service & \multicolumn{1}{l}{ Total } \\
\hline New $<21$ & 48749 & 19119 & 90640 & 158508 \\
New $>20$ & 54568 & 6044 & 63791 & 124403 \\
$1-20$ & 31577 & 10676 & 27617 & 69870 \\
& -25712 & -14066 & -48735 & -88513 \\
Net & 5865 & -3390 & -21118 & -18643 \\
$21-100$ & 41960 & 9742 & 23372 & 75074 \\
& -54206 & -7367 & -30895 & -92468 \\
Net & -12246 & 2375 & -7523 & -17394 \\
$101-500$ & 31185 & 6986 & 17160 & 55331 \\
& -66552 & -9615 & -23395 & -99562 \\
Net & -35367 & -2629 & -6235 & -44231 \\
$>500$ & 21607 & 16925 & 8028 & 46562 \\
& -142318 & -14038 & -8808 & -165164 \\
Net & -120711 & 2887 & -780 & -118602 \\
& & & & \\
\hline
\end{tabular}

the four largest auto assembly firms excluded from the manufacturing totals). New small firms added 158,500 jobs, most of which were in financial and business services. Small existing firms, defined as those employing 100 or fewer workers in 1978, added another 144,900 jobs. Thus, small firms and new small firms accounted for $57 \%$ of all new jobs created between 1978 and 1987. New firms that began with more than 20 people added 124,400 jobs, or $23 \%$ of all jobs, and there is some chance that some new starts may be included within this group. Large enterprises, defined as those employing over 100 workers in 1978 , added 101,900 jobs, or $19 \%$ of all new jobs.

Job loss was concentrated among the larger firms. Firms employing over 500 people in 1978 lost over 165,000 jobs, exclusive of the large auto firms. That amounted to $37 \%$ of all jobs lost in declining and failing non-automobile firms. In contrast, firms employing fifty or fewer workers in 1978 lost 140,000 jobs between 1978 and 1987, which is $31 \%$ of all auto jobs lost outside the large auto companies. If we include the 209,000 jobs lost in the largest firms in the automobile industry, the proportion of jobs lost by the very large firms increases to $57 \%$ while that lost by firms with less than 50 employees drops to $21 \%$.

Job creation and loss in the manufacturing and service industries follow quite different patterns. In manufacturing, job creation is concentrated among new and small firms. The new, as opposed to possibly transplanted firms, and firms employing fifty or fewer people in 1978 accounted for $44 \%$ of the new jobs. Transplants and firms with over 500 employees in 1978 combined accounted for $33 \%$ of the new jobs. The job losses, even excluding automobile assembly, were most evident in the larger firms, with the largest firms (those with over 500 employees in 1978) accounting for almost half the lost jobs. (Again, if we added auto assembly to these numbers, the job loss among the largest firms would be exceptionally high.) Thus, job creation occurs among new and small firms while decline is more characteristic of the largest firms. We suspect this is just another manifestation of the mature nature of manufacturing industries.

Services provide a contrasting picture. Job creation is even more a characteristic of new enterprise. Small firms founded after 1978 accounted for $35 \%$ of all business related service 
jobs created and firms employing 20 or fewer people added another $12 \%$ of all jobs created in this sector. Thus, these new and small firms accounted for nearly half of all the financial and business service jobs created between 1978 and 1987. Suspected transplants and growth among the largest firms accounted for $30 \%$ of the new jobs. ${ }^{6}$ Job loss was also concentrated among the smallest firms. Firms employing twenty or fewer people in 1978 accounted for $40 \%$ of the lost service jobs. Enterprises employing over 100 employees in 1978 accounted for $36 \%$ of the service jobs lost in this period.

The distribution of job loss and gain in services, relative to that in manufacturing reflects two characteristics of the service industry. The first is that service firms tend to be much smaller than those in manufacturing, thus concentrating job loss among small firms. Secondly, and more importantly, the nature and relative youth of the service industries encourage this type of churning, with high birth and death rates. Service industries tend to have many more and smaller new firms, which contributes to a higher failure rate. On the other hand, a certain proportion of the new firms become successful and grow to become mature enterprises. One might envision the service industries as a particularly prolific maple forest where many seeds germinate each year, but few survive.

\section{New firm growth and survival}

Of the 283,000 jobs created by firms new to Michigan between 1978 and 1987, 57\% were in firms with 20 or fewer employees when they first appeared in the data base and nearly $30 \%$ were in firms that started with fewer than 6 employees. Thus, the vast majority of 1987 employement in new firms is coming from smaller, and thus more likely from new entrepreneurial firms.

Our concern is to examine the history of these start-up firms in detail. This analysis is warranted because they provided a substantial proportion of the jobs created in Michigan and because their contribution to long-term growth has been a subject of considerable debate. Following our forest metaphor, we want to know what happens to these seedlings - their survival rate, their growth rate, and how many grow into large enterprises that contribute to long-term economic growth. One hypothesis is that new firms, particularly the very small ones, have a very low survival rate making them an unreliable source of longterm growth. Very high birth and failure rates would lead to the appearance of large amounts of job creation in the short run but little sustained growth. A contrary hypothesis is that some of the new firms will have sufficiently high growth rates to offset the jobs lost by the failing firms. Thus, we want to examine firm survival rates and the job growth rates of these surviving firms.

Our analytic strategy is to examine the firms created each year and follow the survival rate in successive years. We also compute the total employment in these surviving firms and compare that employment with the total number of jobs in the new firms in the original year. For example, assume we had 1,000 new firms with ten or fewer employees in 1979 and that these firms employed a total of 2,000 workers (an average of 2 employees per firm). In each successive year we can identify the number of surviving firms and their total employment. We know that the number of firms will decline each year, but we do not know what happens to total employment. If the survival rate by 1987 is only one-third, but the average employment among these remaining firms exceeds 6 people/firm, total employment will have increased over the long-term because of these 1979 births. We will do this analysis for different size new firms, for manufacturing and services, and for births in each year between 1979 and 1986. ${ }^{7}$ This history of the firms that started doing business between 1978 and 1986 offers important insights into the process of industrial dynamics.

Among very small new manufacturing and business service firms (all these firms started with five or fewer workers), born in the years 1979 to 1984 , only about a third of the new firms survive over an eight year period. This is hardly news. ${ }^{8}$ What is surprising is how consistent these survival rates are regardless of what year the firm started. Firms beginning in the late seventies and experiencing the serious recession several years later, those starting during that recession, and enterprises beginning during the better times after 1983 all seem to fail at the same rate, particularly in business services. These data suggest that much of the new firm creation activity is short-lived, regardless of starting year and current business 
conditions. This is far from the whole picture, however.

The significant question from an economic development perspective is, how many jobs are created over a several year period? The answer is, more than were created initially for the smallest firms. Figures 1 and 2 show the total number of jobs in the firms remaining each year as a proportion of all the jobs created by new firms in a given year. These data are for those firms that began with five or fewer employees. Ratios greater than one indicate that total jobs increased over time, meaning that the job growth of surviving firms exceeded the job loss resulting from failures. For manufacturing, these ratios are consistently above one and can approach two, indicating net job creation over the long-term from these new firms. For services, there is job loss in the short run (ratios less than one) but long-term growth. New manufacturing firms have a higher capacity for job generation than service firms, as indicated by their higher ratios. In terms of total job generation, however, small service firms were more important than manufacturing firms, despite their lower growth. There are simply many more of them. The significant fact in both sectors is that over these nine years, the birth of new firms led to long-term job creation. We do not see the creation and rapid net loss of jobs that are predicted by examining only firm survival rates.

Two simple statistical analyses will help compare the long-term survival and job creation rates of new firms of different sizes and sectors. The first model describes the proportion of firms born

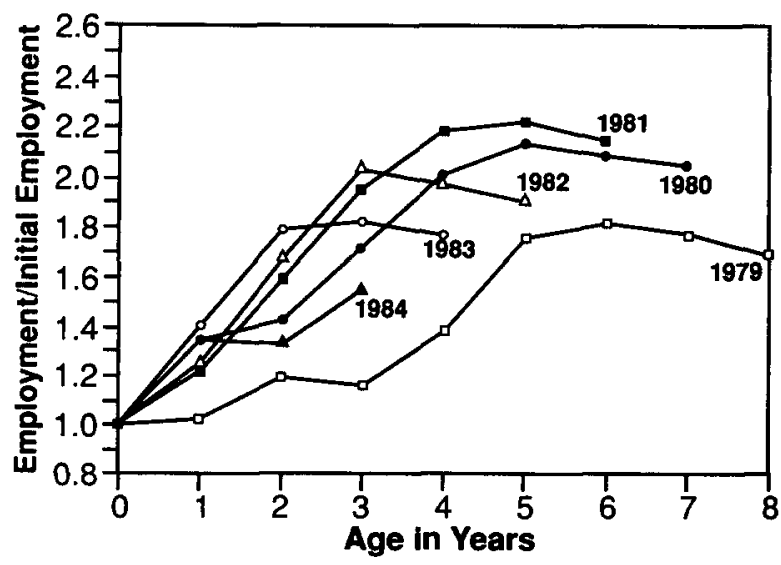

Fig. 1. New firm job growth: Very small manufacturing firms.

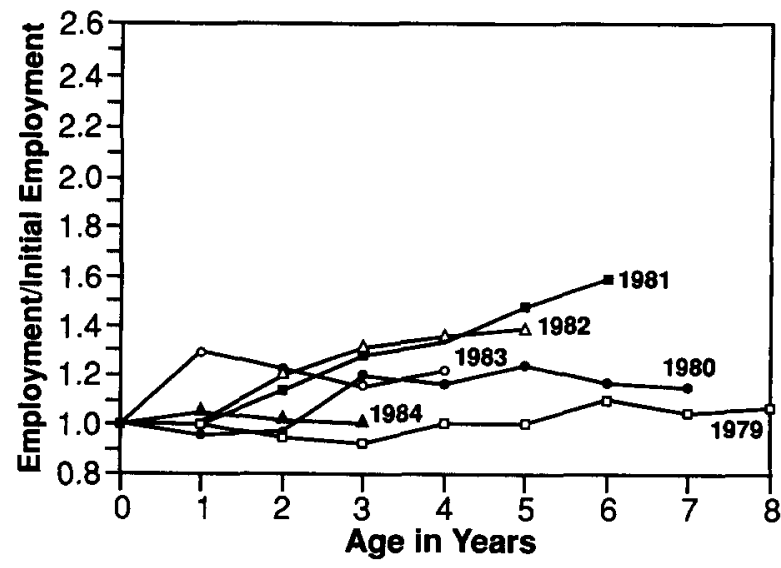

Fig. 2. New firm job growth rates: Very small business service firms.

in given year (year $i$ ) surviving in a later year (year $t$ ) as a function of the firms' age, the year they were born, and the state of the economy in year $t$. The state of the economy is defined as the annual percent change in real GNP. The second model describes the ratio of total employment in year $t$ created by the firms born in year $i$ to their employment in year $i$ as a function of the same variables. ${ }^{9}$ We examine firms classified by whether they had one to five, six to ten, eleven to fifty, and over fifty employees when they first entered the data base and by whether the firms are in manufacturing or business services. ${ }^{10}$

The statistical models predict the survival and job creation rates of different sized new firms for each sector. The estimated coefficients are shown in Tables IV and V. After taking an average of the cohort and period effects we can focus on the expected survival and job creation rates by initial size and sector as the new firms age. ${ }^{11}$

The expected survival rates of firms of different sizes in manufacturing and services show that, as expected, the larger the initial size, the greater the likelihood of survival. The survival rates are slightly higher among manufacturing than among service firms. Among the smallest firms, about a third of the new firms survive after ten years. For services, this figure is just under $30 \%$. There are no surprises here.

The greater surprises are in the estimated employment growth rates. The highest growth rates are in the smallest firms. In manufacturing, after ten years the smallest firms are expected to generate about two jobs for every one created 
TABLE IV

Firm survival rates

\begin{tabular}{llc}
\hline & Manufacturing & \\
\hline Size & Constant $^{\mathrm{a}}$ & Age effect $^{\mathrm{b}}$ \\
\hline $1-5$ & -0.243 & -0.093 \\
& & $(0.004)$ \\
$6-10$ & -0.087 & -0.098 \\
& & $(0.007)$ \\
$11-50$ & -0.112 & -0.087 \\
& & $(0.006)$ \\
$>50$ & 0.020 & -0.068 \\
& & $(0.015)$ \\
\hline & Services & \\
\hline Size & Constant ${ }^{\mathrm{a}}$ & Age effect \\
\hline $1-5$ & -0.285 & -0.111 \\
& & $(0.004)$ \\
$6-10$ & -0.166 & -0.104 \\
& & $(0.005)$ \\
$11-50$ & -0.121 & -0.103 \\
& & $(0.005)$ \\
$>50$ & -0.070 & -0.079 \\
& & $(0.010)$
\end{tabular}

a Composite intercept based on average cohort and cyclical effects.

b Defined as coefficient of age of firm, standard error in parentheses.

initially, despite having two-thirds of the firms fail. For firms that began with between six and ten employees, there are about one and three quarters jobs for every original job. In services, these ratios are about one and a quarter jobs for every initial job for the smallest firms and about 1.05 for the second group of firms. Across sectors and initial sizes, growth rates decline fairly noticeably with age, however.

The second surprise comes when we examine the long-term job creation of the largest firms. These are the firms that began with over fifty employees, and are most likely to be our transplants. In both manufacturing and services, the employment in new large firms is expected to decline over time as growth in surviving firms does not exceed the employment loss in failing and declining firms. During average times, after ten years these remaining firms employed about $80 \%$ of the original work force.

The clear implication of this analysis is that new
TABLE V

Firm growth rates

\begin{tabular}{lcc}
\hline \multicolumn{3}{c}{ Manufacturing } \\
\hline Size & Constant $^{\mathrm{a}}$ & Age effect $^{\mathrm{b}}$ \\
& & 0.255 \\
$1-5$ & 0.231 & $(0.021)$ \\
& & 0.243 \\
$6-10$ & 0.056 & $(0.043)$ \\
& & 0.088 \\
$11-50$ & 0.037 & $(0.036)$ \\
& & 0.046 \\
& & $(0.037)$ \\
\hline
\end{tabular}

\begin{tabular}{lcc}
\hline & \multicolumn{1}{c}{ Services } \\
\hline Size & Constant $^{\mathrm{a}}$ & Age effect $^{\mathrm{b}}$ \\
\hline $1-5$ & 0.029 & 0.088 \\
& & $(0.023)$ \\
$6-10$ & -0.087 & 0.064 \\
& & $(0.027)$ \\
$11-50$ & -0.007 & -0.059 \\
& & $(0.038)$ \\
$>50$ & -0.122 & -0.013 \\
& & $(0.053)$ \\
\hline
\end{tabular}

a Composite intercept based on average cohort and cyclical effects.

b Defined as coefficient of $\log$ (Age of firm), standard error in parentheses.

small firms, our likely entrepreneurial enterprises, are a large source of new jobs initially and they continue to generate new long-term jobs. Conversely, the larger "new" firms, which are more likely to be transplants, provide new jobs initially, but in normal times about $20 \%$ of these jobs are expected to disappear over a ten year period.

\section{E. Summary}

The health of a forest fluctuates from year to year, depending upon rainfall, temperature, etc. and their effect on the rates of birth, death, growth, and decline. In the long run, the forest will get larger or smaller and more or less dense depending upon how these rates react to the ecological environment, the richness of the soil, disease, management practices, and so forth. And, over extended periods, a forest may (will) need to develop new varieties of trees or new strains of existing vegetation in order to adapt to changing circumstances. Similarly, an economy goes through short-term 
cycles, with changes in rates of birth, death, growth, and decline among individual firms depending upon fluctuations in national economic circumstances, federal government policies, and natural conditions. At the same time, it is possible to discern long-term changes in these same rates as firms and industries become more or less competitive, as markets expand and contract, and as technological innovation changes production methods. Lastly, economies also must develop new industries and new versions of existing enterprises in order to adapt to changing global conditions and circumstances.

The concern for policy makers and economic observers should be the rates of birth and longterm job growth and the types of firms experiencing decline and failure. What we may be observing in Michigan is the regeneration of the economic forest. Job loss, even excluding the automobile assemblers, is occurring primarily among the largest durable manufacturing firms and the small service firms. In manufacturing, these losses are likely the result of large, older firms losing their competitiveness in the world economy. In some instances these firms may be simply going out of business or dramatically reducing their activity. In other cases, the firms may be relocating their production activities to other, presumably cheapter, areas of the world. These declining firms are being replaced by a large number of new, small firms. Over the past decade, these new firms have shown a higher rate of employment growth that has led to net long-term job creation. This is the process one hopes to find in a mature forest with a large number of large, older trees.

The finance and business service sectors have shown a very high rate of firm formation, with these firms providing a net long-term increase in jobs. This sector also exhibits higher failure and job loss rates among its smaller firms than observed in manufacturing. Some of this churning may be characteristic of relatively new, infant industries, where a large number of the firms are both new and small, where markets are not well developed, and where start-up and capitalization costs are small. On balance, the service sector is providing a large number of new jobs in Michigan because of the very high rates of birth. The question at this point is whether these sectors will stabilize and experience lower failure rates, and possibly lower birth and growth rates, than we see during the early and mid-1980s.

Lastly, this detailed analysis of the economic trees demonstrates that new firm creation can be a source of large numbers of new long-term jobs. Despite low survival rates, these new entrepreneurial firms are sources of long-term job growth, with more jobs being created by their growth than are lost by failures. Thus, there is far more to new business creation than just the conventional "churning."

\section{Studying mergers and acquisitions}

For most purposes, the careful handling of predecessor and successor records in the MESC file allows the researcher to avoid the aggravation and error which changes in ownership would otherwise bring about. However, these changes in ownership can be of interest in their own right; given the longitudinal nature of the data, they can be used to study either the antecedents or consequences of such changes. A recent study by Brown and Medoff (1988) provides an example of this type of research.

A number of well-publicized corporate takeovers have been followed by equally publicized reductions in employment or wages once the new management is in place. These reductions have contributed to legislative proposals to make such takeovers more difficult. But it is not clear whether these well-publicized cases are representative of mergers and acquisitions in general. Acquisitions may save otherwise failing firms from closing altogether, or provide access to capital to allow an otherwise stable unit to expand. To resolve this controversy, one needs to follow wages and employment following changes in ownership.

The term "merger" is generally used to describe a situation where the assets and (at least initially) the work force of a firm are acquired by another existing firm. As described in Section II, the MESC data allow one to follow both firms prior to the sale, and the combined entity afterward. ${ }^{12}$ But firms are also sometimes sold to new owners without becoming part of another organization indeed, such "simple sales" are a good deal more common than mergers in the MESC data.

A third and more puzzling type of change of ownership also occurred fairly frequently in the 
data: firm $B$ is acquired by firm $A$, but the employment of the combined firm does not increase appreciably at the time of the acquisition. While one can think of situations where one would expect such "asset only" acquisitions to be commonplace (e.g., firm B's main asset is a building, into which firm A expands, without retaining any of B's workers) the frequency of such patterns was somewhat surprising. Finally, the predecessorsuccessor relationship is triggered by changes in form of ownership (e.g., a change from partnership to corporation) even without a change in the identity of the owners. These "reorganizations" were essentially identified and then ignored in Brown and Medoff's study, both because they were somewhat tangential to their main interest and because one suspects that they are particularly likely to reflect planned expansions rather than just causing them.

Several challenges arise in assigning individual acquisitions to these four categories (mergers, simple sales, assets-only sales, and reorganizations). First, a firm acquired by an out-of-state purchaser will have no pre-sale successor employment, and hence be counted as a simple sale rather than a merger. Second, employment fluctuations occur apart from any change in ownership, and this makes it difficult to decide whether some acquisitions are mergers or assets-only sales. ${ }^{13}$ Third, some reorganizations may in fact be accompanied by a genuine change of ownership.

Table VI gives the number of firms and average size of firm for those engaged in these four types of change of ownership, plus those involved in no such change over the period from 1979 through the third quarter of 1984 . There are several striking features of the table. First, mergers are actually quite rare in the data, and, as noted earlier, assets-only sales are perhaps surprisingly common. Second, as previous sections of this paper have noted, the typical firm is small roughly 20 workers. Third, firms involved in simple sales and reorganizations are somewhat smaller than the typical firm. Fourth, those involved in assets-only acquisitions or mergers are larger than average. In Table VI, size is calculated by the size of both the predecessor and the successor prior to the transaction. Separate analysis of predecessors and successors shows that the predecessor is about one-tenth the size of the
TABLE VI

Number and average size of firms by type: 1978

\begin{tabular}{lcc}
\hline Type of firm & $\begin{array}{l}\text { Number of } \\
\text { observations }\end{array}$ & $\begin{array}{l}\text { Average } \\
\text { employment }\end{array}$ \\
\hline No predecessor & 173445 & 29 \\
Simple sale & 7905 & 21 \\
Assets-only & 3138 & 130 \\
Merger & 479 & 264 \\
Reorganization & 17578 & 10 \\
\hline
\end{tabular}

Notes: Number of observations with no predecessor is equal to the figure reported by Brown and Medoff multiplied by five, since their no-predecessor sample was a 1-in-5 sample of these firms. 4,155 firms which were involved in 1978 or fourth quarter of 1984 acquisitions, or whose "type" could not be determined due to missing data, are excluded from the table. Average employment is calculated from the sub-sample of firms with positive employment and wages in each year.

successor in asset-only acquisitions, and about one-third as large for mergers.

Brown and Medoff traced employment and wages in the period following these acquisitions, compared to what (they estimated) would have happened in the absence of any change of ownership. What would have happened is in effect based on pre-acquisition paths of wages and employment, plus dummy variables for one-digit industries. They focused on 1981 and 1982 acquisitions, in order to have both several pre-event years (to use in predicting what would otherwise have happened) and several post-event years (to check whether any immediate impacts are durable).

In general, the MESC data show relatively moderate responses to the various kinds of acquisitions, with inconsistent patterns across types of acquisition. Firms which are part of simple sales have post-event wages about $5 \%$ lower than they would otherwise be, but employment which is roughly $9 \%$ higher. Firms which are part of assets only acquisitions have wages which are about $5 \%$ higher than they would otherwise be, but employment about 5\% lower. Mergers are associated with wage declines of about $4 \%$, and employment growth of about $2 \%$. The repetitive use of the qualifier "about" is motivated by the fact that the estimates are sensitive to various (largely arbitrary) ways of undertaking the analysis (e.g., focusing on changes in or rates of change of employment), and differences (particularly for 
employment) between 1981 and 1982 acquisitions.

One specification check which did not greatly influence the results was moving from the main sample of firms which reported employment and payroll data in each year (1978-84) to a sample which included firms which died in 1982-83. However, adding in these deaths increased the sample by about $15 \%$, underlining the well-known fact that death rates of firms are quite high if one succeeds in including a large enough fraction of the newest and smallest ones.

In assessing these results, it is important to keep two qualifications in mind. First, our firms are in general much smaller than the very large firms which grab the lion's share of media attention. Acquisitions involving firms small enough to be owner-managed may have different consequences than the large publicly-owned ones one reads about in the newspaper. Knowing whether this is so requires similar work focused on larger firms. Lichtenberg and Siegel (1987) find, using Census Longitudinal Establishment Data file information for manufacturing plants (with much larger average unit size than in the MESC data), establishments which underwent ownership changes had slower growth (relative to other units in their industry) prior to the change, but similar employment growth rates afterward. Shleifer and Summers (1988) argue that large hostile takeovers are likely to be followed by particularly adverse consequences for workers. Second, our "wage" measure is earnings per worker, and it reflects (in addition to the wage) variations in hours worked and to the composition of the work force. If a firm adds workers who are paid less than the firm's average (as would often be the case), the average wage as measured in these data would fall; conversely, if the firm discharges (recently hired?) workers who earned less than its average its average wage would rise - in both cases even if the wage of those who remain employed does not change at all. In addition, if a merger leads to the departure of the (highly paid) head of the acquired firm, average wages would fall, even if the wages of those workers who remained were unaffected.

\section{Conclusion}

The results presented in the two preceding sec- tions provide examples of two types of research for which the MESC data are well suited. But certainly they do not exhaust the set of topics which these data could explore, nor even the topics for which the data have advantages which are not available in other data bases. While a detailed comparison of the MESC data and other data bases is beyond the scope of this chapter indeed, the volume as a whole serves to provide an overview comparison - it is worth pointing out several features of the data base which may make it particularly suitable for certain research topics. First, it is based on regularly reported administrative records, including (at least in principle) all Michigan firms with at least one employee. Second, in addition to the detailed industry and employment data which nearly any longitudinal business data base is likely to include, there are payroll data as well, which permit contrasts in the level and change of earnings per worker across firms of different types. Third, the payroll and employment data are quarterly rather than annual, so the timing of expansions and contractions can be determined with considerable precision.

The MESC longitudinal data base currently incorporates ES202 data for the period from the third quarter of 1978 through the fourth quarter of 1988. Annual updates to the data base are planned. A longitudinal data base, similar to the MESC data base has been constructed from Illinois Department of Security ES202 and CTS (Contribution Tax System) records. This data base, which spans the period from the second quarter of 1982 through the fourth quarter of 1986, also uses the OSIRIS hierarchical file format. It was constructed through a joint effort of the Illinois Department of Employment Security, the University of Illinois Chicago Area Geographic Information Service (CAGIS) and the University of Michigan Survey Research Center. A consortium of users from both government and industry contributed to support the construction, updating, and analysis of the Illinois data base. Regular reports which show employment change by SIC and geographic area are generated by CAGIS and distributed to consortium members. Members can also request special analyses.

The current Michigan and Illinois data bases can track employment change within each state. However, using each of these data bases, there is 
no way to distinguish a firm which goes out of business ("dies") from a firm which moves out of the state. In the future, it may be possible to link data bases from states within a region - such as the Great Lakes states - and be able to analyze employment change within a region rather than only within a state.

The MESC data files contain sensitive employment and payroll information about Michigan companies and are by law confidential. Moreover, by law only certain state and federal government agencies and university groups engaging in research of public nature can be granted access to the MESC data. Nevertheless, MESC's arrangements for researchers' use of the data are intended to stimulate use of the data within the constraints which confidentiality imposes.

The University of Michigan's Institute for Social Research has been granted confidential access to the original MESC files for the purpose of constructing the longitudinal data base. A special set of security procedures is being used by ISR to insure the confidentiality of the MESC data. Although ISR will maintain the longitudinal data sets (both the structured and rectangular files), the Michigan Employment Security Commission retains ownership of these files and the right to control access to the data. Consequently, inquiries about availability of the data should be directed to the Bureau of Research and Statistics of the MESC. ${ }^{14}$

\section{Appendix}

\section{A. Employer Master Records}

There were 101 data fields in the EMR. The EMR fields which were of particular importance in the construction of the longitudinal data base are described below:

\section{(1) Employer Number (UI):}

This a six-digit identification number which also appears on the company's ES202 records. The UI number uniquely identifies a company and was used to merge the EMR record with the ES202 records for each company.

(2) Succeeded by Number:

This field contains the Employer Number (UI) of the firm which is a "successor" to the firm named in the record. A firm which has a number in this field is considered to be a "predecessor" firm. The relationship of predecessors and successors and the handling of these relationships in the longitudinal data base is described in Part $\mathrm{C}$.

(3) Predecessor Number:

The Predecessor Number field contains the UI number of the most recent predecessor to a firm named in the record. Although a firm could have more than one predecessor at a given point in time (merger) or could have a series of predecessors going back in time, there was room for only one predecessor UI number on the EMR record.

(4) Date of Acquisition:

This date appears on a successor company's record and shows the date that the predecessor company was acquired, merged, etc.

(5) Termination Date:

This date appears on the Predecessor record as the date the company was acquired. A date in this field also appears on the records of firms which go out of business. However, there can be a time lag of several quarters from the date of the last ES202 forms filed to the date of termination. Thus the termination date may be several quarters later than the actual "death" of a company.

(6) Industry Code:

This code is the four-digit SIC code. ${ }^{15}$

(7) Area Code:

The area code is a two-digit county code used by the State of Michigan. It does not correspond to the commonly used Federal Information Processing Standard (FIPS) code, but can be converted to a FIPS code.

(8) Multi-Unit Code:

This field is either blank or contains a flag indicating that the record is a Master record ("M") or a Detail record ("D"). About 400 large multi-establishment firms are required to report thier employment for each separate SIC for each county. These county by SIC reports are called "Detail" records. Detail records are aggregated by MESC to create a "Master" record for the firm.

(9) Experience Beginning Date:

This date serves as the "birth" date of the company. This is the date on which the firm or its predecessor (if it has assumed its predecessor's experience rating) became liable under the MESC regulations. 


\section{B. ES-202 records}

The ES202 form is a quarterly report filed by each company having at least one paid employee and being required to participate in the MESC unemployment insurance program. MESC maintains quarterly files of ES202 reports on magnetic tape. Nineteen of these ES200 tape files, 1978-3rd quarter through 1983-1st quarter were used in building the original MESC data base. The important ES202 fields used in constructing the data base are described below.

\section{(1) Employer Number:}

This is the six-digit identification number which was used (except in the case of Detail records) to link ES202 records with EMRs. ${ }^{16}$

(2) Multi-Unit Code:

This field corresponds to the field with the same name in the EMR record. It is either blank or contains an " $M$ " indicating a Master record or a "D" indicating a Detail record.

(3) Multi-Unit Suffix Number:

This two-digit number is used to distinguish among Detail records having the same UI number. For example, a firm with 10 plants in separate counties would have a Master record with an "M" in field (2) and blanks in field (3). The Detail records would have the same UI number as the Master record, a " $D$ " in field (2) and suffix code numbers " 01 " through " 10 " in field (3).

(4) Industry Code:

This is the SIC code. The SIC code on the EMR would be the firm's current SIC code. The SIC code may have changed over time and the SIC on the quarterly ES202 file would be the SIC code for that quarter.

(5) Area Code:

This is the code for the county in which the firm was located in the quarter. The Area Code on the EMR is the county in which is currently located. In the case of a "Master" record, the area code is the location of the company's headquarters.

(6) 1st, 2nd, 3rd Months Employment:

These fields have the firm's employment for each of the three months of the quarter. Four consecutive quarters of no employment, or no ES202 record (missing data on employment) was used to determine the date of "death" of a company. It is impossible to determine from the data available on the file whether a "death" of a company reflects the company going out of business or the company leaving the state.

(7) Gross Payroll:

This is the amount of the firm's quarterly payroll.

(8) All Data Estimated Code:

At "E" in this field indicated that the company did not file an ES202 report for that quarter and that the MESC estimated all of the data. An " $E$ " in this field was treated as zero or missing data in employment in determining the quarter of "death" of a firm.

\section{Special types of records and relationships}

There were four types of records in the MESC file which required special treatment in constructing the longitudinal data base: Predecessor Records, Successor Records, Master Records, and Detail Records. There are relationships between the Predecessor and Successor records and between Master and Detail records which need to be taken account of in the longitudinal data base. These relationships are described below.

\section{Predecessor/Successor Relationships}

An important consideration in constructing the longitudinal data base was to maintain predecessor-successor relationships. Predecessor records must be linked to Successor records so that the firms involved could be treated as a single "continuing" firm rather than a "death" of a predecessor and a "birth" or growth of a successor. The employment and payroll history of a firm would include the employment and payroll of any predecessors for the quarters that the predecessors existed.

In order to accomplish the linking of predecessors and successors, a FORTRAN program was written to search through an indexed file of predecessors for up to three predecessors back in time. The UI numbers for the first, second, and third predecessors and the current successor were added to each EMR predecessor record. In addition to allowing for three predecessors back in time, the program allowed for up to three merger partners for any successor.

The algorithm uses the successor field rather than the predecessor field to link the records. ${ }^{17}$ All employment and payroll data were aggregated by quarter for all predecessor records 
linked to the same current employer. These aggregated records were added to the longitudinal data base.

\section{Master/Detail Records}

About 400 larger firms which have establishments in several counties and in various SIC categories are required by law to report payroll and employment separately for each SIC category within each county. The detailed reports are used by the U.S. Department of Labor to produce federal statistical summaries. The MESC aggregates the Detail reports for each firm, creating a "Master" record for the firm. Therefore, this group of about 400 firms have both Master and Detail records in the MESC file. Employment amounts appear on both Master and Detail records. Payroll amounts are only on the Detail records. Care must be taken when using the file to exclude either Master or Detail records in order to avoid double counting the companies. All other firms have a single EMR which is neither a Master nor a Detail record.

\section{Notes}

* Judith Connor and Steven Heeringa are primarily responsible for Section II and the Appendix, John Jackson for Section III, and Charles Brown for Section IV.

1 A Successor is an employing unit which takes over substantially all of the employing enterprises of another employing unit, the Predecessor. For the purpose of determining the Contribution Rate for unemployment insurance, a Successor firm take on the liability rating of the Predecessor firm. MESC maintains records of each merger or sale in which there is a Successor and one or more Predecessors.

2 Beginning in 1985, a new information system was installed for MESC which no longer has an Employer Master Record. However, this record-type can be constructed from an "extract" produced by the new system.

3 The Experience Date may not reflect the true "birth" date when a company has been "reinstated" after several quarters of non-reporting. This is a rare occurrence.

${ }^{4}$ A further, more methodological addition is based on the fact that, unlike most previous studies, ours is based on state administrative records rather than the SBA's longitudinal file (based in turn on Dun and Bradstreet data). The D\&B data are known to have several problems, which researchers have tried to address in different ways: under-reporting of branches, newer firms, and smaller firms; questions about handling of records which have not been updated; and questions about whether changes of legal status are mistakenly recorded as deaths (Storey and Johnson, 1987).

5 These new jobs appear as an expansion, as EDS previously employed people in Michigan.
${ }^{6}$ It is important to keep in mind that over a third of the growth among firms employing between 100 and 500 people in 1978 was accounted for by GM's acquisition of EDS.

7 A birth is defined as a firm that did not have employment in any prior year.

8 Phillips and Kirchhoff (1989) report that $37 \%$ of all firms started with 1-4 employees in 1976-78 survived to 1984 .

9 These models are analogous to the age, period, and cohort models used in social demography.

${ }^{10}$ Our analysis omits one business service firm. This firm provided temporary employees, started in the largest category, and had an abnormally high employee growth rate (over $900 \%$ ). Inclusion of this firm strongly distorted the model for employment growth among large service firms.

11 The average cohort effect is the average of the coefficients on the birth year variables and the average period effect is the average of the annual growth rates in GNP for this period multiplied by the coefficient on cycle in the equation.

12 In a minority of cases (large firms which report county-byindustry aggregates of their establishments), it may be possible to follow separately the "old" and "new" pieces of the firm.

${ }^{13}$ Suppose, e.g, that frim B with 10 workers, is acquired by firm $A$, whose employment rises by 2 workers at about the time of the sale. It is hard to tell whether $B$ was acquired by $A$ which then dismissed 8 of its workers, or B was closed, A bought the assets, and expanded its own work force by two workers.

14 Address: 7310 Woodward Avenue, Detroit, Michigan (Zip). Telephone: (313) 876-5439.

15 The SIC code was used to divide the data base into three parts: (1) manufacturing, wholesale, and retail (SIC codes beginning with 2, 3, or 5); (2) services (SIC codes beginning with 6,7 , or 8); and (3) other SIC's which includes agriculture, mining, construction, transportation, utilities, and government (SIC codes beginning with $0,1,4$, or 9) or missing data on SIC code. Missing data for SIC was found on 6,260 (out of 326,446 ) records. This subdivision was necessary because of the very large size of the data base and the desire to keep files to a maximum of two 2,400-foot $(6,250$ BPI) tapes, to facilitate file updating and other data management operations.

${ }_{16}$ In the case of Detail records the linking required the county code and SIC code in addition to the UI number.

17 This is because, in a merger situation, each partner will have the UI number of the acquiring firm in its "succeeded by" field. However the current "successor" firm will show the UI number of only one predecessor in the "predecessor" field. Therefore, in linking predecessors with successors, the program searches for up to three predecessor records having a given successor UI number. It stores these predecessor ID's in an array and then searches for up to three predecessors for each of these second level predecessors.

\section{References}

Acs, Zoltan, and David Audretsch, 1989, 'Technological Regimes, Learning, and Industry Turbulence', Wissenschaftszentrum Berlin für Sozialforschung, Working Paper, 89-12. 
Armington, Catherine, and Marjorie Odle, 1982, 'Small Business: How Many Jobs?', Brookings Review 20, 14-17.

Birch, David, 1981, 'Who Creates Jobs?', Public Interest 65, 3-14.

Birch, David, 1987, Job Generation in America, New York: Free Press.

Brown, Charles, and James Medoff, 1988, The Impact of Firm Acquisitions on Labor', in Alan Auerbach (ed.), Corporate Takeovers: Causes and Consequences, Chicago: University of Chicago Press, pp. 9-25.

Dunne, Timothy, Mark, Roberts, and Larry Samuelson, 1989, 'Plant Turnover and Gross Employment Flows in the U.S. Manufacturing Sector', Joumal of Labor Economics 7, 48-71.

Leonard, Jonathan, 1987, 'In the Wrong Place at the Wrong Time', in Kevin Lang and Jonathan Leonard (eds.), Unem- ployment and the Structure of Labor Markets, New York: Basil Blackwell, pp. 141-163.

Lichtenberg, Frank, and Donald Siegel, 1987, 'Productivity and Changes in Ownership of Manufacturing Plants', Brookings Papers on Economic Activity 3, 643-673.

Philips, Bruce, and Bruce Kirchhoff, 1989, 'Formation, Growth, and Survival: Small Firm Daynamics in the U.S. Economy', Small Business Economics 1, 65-74.

Shleifer, Andrei, and Lawrence Summers, 1988, 'Breach of Trust in Hostile Takeovers', in Alan Auerbach (ed.), Corporate Takeovers: Causes and Consequences Chicago: University of Chicago Press, pp. 33-56.

Storey, D. J. and S. Johnson, 1987, Job Generation and the Labour Market, London: Macmillan.

U.S. Small Business Administration, 1988, The State of Small Business, 1988, Washington: Government Printing Office. 